\title{
Aa. Vv., «Bulletin d'Informations Proustiennes», n. 40
}

Geneviève Henrot Sostero

\section{(2) OpenEdition \\ 1 Journals}

\section{Edizione digitale}

URL: http://journals.openedition.org/studifrancesi/5750

DOI: 10.4000/studifrancesi.5750

ISSN: 2421-5856

\section{Editore}

Rosenberg \& Sellier

\section{Edizione cartacea}

Data di pubblicazione: 1 septembre 2011

Paginazione: 451-452

ISSN: 0039-2944

\section{Notizia bibliografica digitale}

Geneviève Henrot Sostero, «Aa. Vv., «Bulletin d'Informations Proustiennes», n. 40», Studi Francesi [Online], 164 (LV | II) | 2011, online dal 30 novembre 2015, consultato il 13 janvier 2021. URL: http:// journals.openedition.org/studifrancesi/5750 ; DOI: https://doi.org/10.4000/studifrancesi.5750

Questo documento è stato generato automaticamente il 13 janvier 2021.

\section{(c) (i) (9)}

Studi Francesi è distribuita con Licenza Creative Commons Attribuzione - Non commerciale - Non opere derivate 4.0 Internazionale. 


\title{
Aa. Vv., «Bulletin d'Informations Proustiennes», n. 40
}

\author{
Geneviève Henrot Sostero
}

\section{NOTIZIA}

«Bulletin d'Informations Proustiennes», n. 40, 2010, 203 pp.

1 Puntuale organo e testimone delle principali attività proustiane in Francia e nel mondo, il «Bulletin» festeggia il suo quarantesimo numero annuale, nonché la quiescenza di uno dei suoi storici fondatori, Bernard Brun; dal 1975 infatti, la rivista ha raccolto sotto la sua direzione i lavori della scuola internazionale di genetica proustiana, proponendone una diffusione coesa e un serrato dialogo teorico e critico. Questo compito di lunga lena è oramai assolto da Nathalie Mauriac Dyer, che cura sia la rivista che l'organizzazione dei seminari.

2 Il volume n. 40 si articola come da tradizione consolidata attorno a diverse sezioni: inediti, studi genetici, saggi critici, teorie e letture, notizie d'aste di manoscritti e corrispondenze (pp. 163-185), bibliografia (pp. 199-203) e tesi recentemente discusse o in corso (p. 203).

3 Nella prima sezione («Inédits»), Pyra WISE rende disponibili ai lettori ulteriori diciotto inediti proustiani, tra lettere, note, cartoline, dediche e biglietti scritti o ricevuti dall'autore (Lettres et dédicaces inédites de Proust et de quelques correspondants, pp. 9-28). La seconda sezione («Genèse») raccoglie due saggi. Di Julie ANDRÉ (Plan, scénarios, résumés. Hypothèses sur la construction du début $d u$ Cahier 46, pp. 31-44) mostra come il fatto di emettere ipotesi per ricostruire la genesi dei quaderni proustiani rimanga una sfida infinitamente complessa e ricca di sorprese. La scrittura "a processo" che praticava Proust non mancava mai di distorcere dal loro iniziale obiettivo i tentati "piani" e le vane "scalette", che presto si trasformavano in riassunti o esordi di stesura. Laurence TEYSSANDIER indaga Sur quelques aspects de la genèse de la soirée Verdurin (pp. 45-54) per vedere come, in sole due campagne tardive di scrittura (1915 e 1916), l'episodio riesca a 
tessere insieme diversi fondamentali "fili" del romanzo: narrativo, estetico, mondano, omosessuale.

Il «Dossier» tematico ripropone gli interventi al seminario Proust et la poésie, organizzato nel 2009-2010 da Philippe Chardin presso l'École Normale Supérieure. Bertrand MARCHAL torna sulla polemica che oppose Proust et Mallarmé attorno all'oscurità in letteratura (pp. 57-75). Michel SANDRAS, peraltro specialista del poème en prose nonché autore di una recente monografia Proust ou l'euphorie de la prose (Champion, 2010), tenta di definire l'originale pratica che ebbe Proust del poema in prosa nelle sue precoci pubblicazioni in riviste simboliste (Proust et le poème en prose fin de siècle, pp. 77-92). In D'un Baudelaire l'autre, lecture critique du "soleil rayonnant sur la mer» (pp. 93-104), Matthieu VERNET identifica le varie facce del Baudelaire praticato da Proust, focalizzando una netta evoluzione tra il Baudelaire fruito da lettore e il Baudelaire interiorizzato come modello di scrittura; un solo verso, già oggetto di riflessioni da parte di Antoine Compagnon, consente di gettare luce su questa evoluzione - o questa rottura - al termine della quale Proust approda alla sua personale scrittura. A valle di Proust, alcuni grandi poeti hanno visto in lui un modello da meditare, così René Char; tale fiducioso riconoscimento induce il critico a chiedersi quale potesse essere la concezione proustiana di poesia (Christine DuPouY, «Le Poète Marcel Proust» (René Char) ou la poésie vue par un romancier, pp. 105-115). Sophie DUVAL, autrice de L'Ironie proustienne. La vision stéréoscopique (Champion, 2004), prosegue qui le sue analisi della commistione prettamente proustiana tra visione poetica e visione umoristica, unione sancita sia in francese che in italiano dalla polisemia della parola prestige/prestigio (Prestiges, miracles et tables tournantes. Métaphore humoristique, analogie universelle et poésie astronomique, pp. 117-136).

5 La quarta sezione («Théories et lectures») propone due saggi. Con Proust lecteur de Henry Bordeaux: Sainte-Beuve retrouvé? (pp. 139-150), Chizu NAKANO s'interessa all'opinione "poietica" che manifestava l'autore nei confronti di una tecnica strutturale romanzesca molto cara ai suoi contemporanei, quale l'iscrizione del romanzo nel romanzo, ovvero la mise en abyme. Infine, Takami suzuKI, autrice di una tesi sulla Notion de croyance chez Proust (Università di Strasburgo, 2010), svolge in La Croyance en mouvement. Images de la mer et de l'atmosphère (pp. 151-159) uno studio lessicale di taglio esaustivo del termine croyance nell'opera. Una rigorosa prospettiva diacronica, unita a una descrizione analitica delle componenti concettuali del termine sul doppio asse del "grado di garanzia oggettiva" e del "grado di fiducia soggettiva", consente alla studiosa di spiegare come, lungi dal costituire un paradosso, la presenza delle due accezioni del termine nell'opera si sviluppi in una chiara e coerente evoluzione legata alla progressiva maturazione del Narratore nell'ambito della sua visione del mondo. 